\title{
Contour Tones in Igbo: 'Where They Come from'
}

\author{
Chikelu Ihunanya Ezenwafor \\ Scuola Normale Superiore, Pisa, Italy
}

\begin{abstract}
Contour tones are typically predominant in tone languages operating a contour system in contrast with tone languages operating the register system. This paper examines the underlying and surface characterization of contour tones (rising and falling tones) at the lexical level in Igbo. Adopting the Autosegmental approach originally proposed by Goldsmith (1976), it reinforces the composite nature of both contours in Igbo. From the data, evidence is given that contour tones in Igbo are mere surface features which are motivated by some underlying rules that arise from the merging of tone at morpheme boundaries, historical loss of segments and the association of a floating tone. The two rules are identified are the deletion and docking rule. The manifestation of the latter is premised on the application of the former. The application of both rules is equally dependent on the fulfilment of some tone contour conditions such as presence of morpheme boundary, occurrence of contrasting tones at the morpheme boundary, similarity of vowels. The data used for this study are mostly individual words (place names and general nouns). These nouns are however morphologically derived complex words. The analysis shows that contour tones are usually induced at morpheme boundaries. Again, there is always a collapse of the contrasting tones realised on the tone bearing units (vowels) at the morpheme boundary. The morpheme boundary as used in this context and as applicable to Igbo is restricted to free morphemes. The first morpheme whose vowel is always affected by the deletion rule could start losing its original meaning overtime.
\end{abstract}

Index Terms - floating tone, morpheme boundary, asynchrony, deletion and docking rules

\section{ETHNOLINGUISTIC INFORMATION}

Igbo is an indigenous language (with many dialects) spoken in Nigeria. The term Igbo is used simultaneously to refer to the language and its speakers. It is spoken approximately by about 20 million people in the South-eastern region of the country. Igbo is also attested to be spoken in Cameroon/Equatorial Guinea as a minority language by about 30,000 people (Joshua Project, 2009). It is classified under West Benue Congo subfamily of the Niger Congo language family (Williamson and Blench, 2009).

\section{Introduction}

Many of the world's languages are largely tonal. A tone language being one that employs the use of tone for meaning distinction in the lexical level, grammatical level or both. Tone is therefore a variation in pitch that enters as a distinctive factor in the lexicon or grammatical constructions of a language. According to Pike (1948) "A tone language is one in which contrastive pitch levels do not merely form the intonation tune of a sentence but enters as a distinctive factor into the lexical elements of the language". In other words, tone distinguishes between the meanings of words with otherwise identical phonemic composition. Similarly, Yip (2002) opines that 'a language with tone is one in which an indication of pitch enters into the lexical realization of at least some morphemes. Gussenoven (2004), equally views tone as a phonological category that distinguishes the meaning of words or utterances. Many definitions of tone however lay more emphasis on the phonemic realisation of tone at the lexical level alone. It might be the case that many tone languages apply tone at the lexical level, but there still exist languages where tone tends to apply strictly at the grammatical level alone. Over the years, there has been a tradition of classifying tone languages into register and contour tone systems based on the nature of tone. The register tone system is largely associated with the tone systems of African languages and only loosely/minimally with contour tones while Asian languages like Chinese typically operate the contour tone system. While register tone register tones are analysed as being level (maintaining a certain level of stability), contour tones are analysed as gliding from one pitch level to another, hence being unstable. More than level tones, contour tones are phonetically subject to different interpretations. While contour tones of Chinese for are seen as unitary units, contour tones in African languages are mostly seen as being composite (comprising of two consecutive level tones). "Contour tones in African languages are a surface phenomenon which needs decomposition into underlying tonal melodies. The fact that the beginning and end points are always identifiable means that contour tones can be split up into their components" (Lojenga 2012). In the subsequent sections, we give a brief review of tone in Igbo, an overview of the theoretical framework adopted, an overview of the phonological account of contour tones in Igbo, then the presentation of data and analysis and the conclusion of our findings.

\section{OVERVIEW OF TONE IN IGBO}

Igbo operates a register tone system with two basic level tones (high, low) and a downstep (a reduced high). It also has two contour tones that are not particularly distinctive. Level tones in Igbo function lexically in distinguishing 
otherwise phonemically identical words. In other words, tone is manipulated contrastively to realize minimal pairs and sets. Below are some examples;
1) ákwà 'cloth'
ákwá 'cry'
àkwà 'bed'
àkwá 'egg'
2) òké 'rat'
òkè 'share'
ókè 'boundary'
óké 'male'

At the grammatical level, tone is vital in differentiating relative constructions from declarative constructions. For example:

3a) Àdá màrà ńmā 'Ada is beautiful'

3b) Àdá mārā mímā 'Ada who is beautiful'

4a) Òbí zùrù óhí jī 'Obi stole yam'

4b) Òbí zūrū óhí jī 'Obi who stole yam'

Observe that the constructions in examples (3b) and (4b) are relativized by the tonal modification of the verbs mara and zuru.

Tone is equally functional in distinguishing between interrogative and declarative constructions in Igbo. Consider the following examples:

5a) Ó zùrù óhí égō

5b) Ò zùrù óhí égō? 'Did he steal money'

6a) Ó gbàrà égwú 'She danced '

6b) Ò gbàra égwú? 'Did she dance?'

Note that the distinction between the interrogatives and declaratives as exemplified above is signalled by a tonal change on the 3rd person singular pronoun ' $\mathrm{O}$ ' which bears a high tone in the declarative construction but a low tone in its interrogative counterpart.

The relevance of tone at the grammatical level is also evident in associative/specific constructions (cf. Williamson 1972). The inherent tone of lexical items in Igbo often changes when moved into such constructions. The following examples are illustrative;

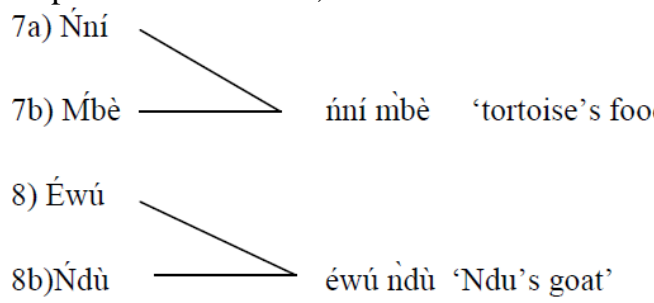

The high tone of the first syllable in example $(7 \mathrm{~b})$ is replaced with a low tone in the specific/associative construction to realize a 'possessive' meaning. This is equally applicable to example ( $8 b$ ) where this same high tone is substituted with a low tone.

Two contour tones are posited for Igbo; the rising $(\checkmark)$ and the falling $\left(^{\wedge}\right)$ tones. There has been a long tradition of analysing these contours as composite. Though contour tones attested in Igbo, their occurrence remain relatively minimal and are not assigned much distinctive status at the lexical and grammatical level. So far, studies on Igbo contours in Igbo are largely restricted to grammatical constructions as seen in (Nwachukwu 1995, Emenanjo 1978). Emenanjo (1978) explains the occurrence of what he calls 'the high- falling-to-low tone. This tone is grammatically motivated as it always occurs on the last syllable preceding the verb in the indicative form". He buttresses his point with the following example:

9) Úlǔ gawara ahia 'Ulu went to market'

Nwachukwu (1995) on the other hand posits the occurrence of contour tones as being induced by certain grammatical constructions (including subject relative clauses. Ugorji (2008) however presents alternative analysis on purely phonological grounds, moving away from the syntactic conditions posited earlier. We shall return to this alternative analysis in section 4.0. An important point to note is that none of these accounts are strictly geared toward individual lexical items but rather as used in specific grammatical constructions. Ugorji (2008) though includes some lexical words in form of personal names in his account.

\section{THEORETICAL FRAMEWORK}


This work adopts a multi-linear approach as developed in Goldsmith's (1976) Autosegmental theory which has been modified over the years though the original idea has been retained. The focus of autosegmental theory is the representation of segmental and non segmental features into different layers or tiers. The non segmental features like tone are otherwise termed autosegments. This is in recognition of the fact that separate rules could apply independently to these different tiers. Vanderhulst et al (1988) explain that autosegmental phonology proposes that the standard onetiered representation (as applicable in the generative framework) be split into several tiers, each constituting a linear arrangement of segments. These segments are then linked to each other by association lines that indicate how they are to be articulated. One should observe that there is not always a neat or one- to- one correspondence between the two separate tiers (with emphasis on tone). Over the years, many African tone languages have played a vital role in the development of this theory. One of such languages which happens to be our major concern is Igbo. Igbo has been attested as a register tone language with occasional manifestation of non significant /significant contour tones; the rising $\left({ }^{\wedge}\right)$ and falling ( $\left(^{(}\right)$. The problem however is on the representation of these contour tones. Whatever the case, this problem is not peculiar to Igbo but to other tone languages with the manifestation of contour tones. One of the typical arguments that often arise in the autosegmental theory is on the analysis of contours as being unitary or as underlyingly composite. This problem was of course a carried over from the generative tradition which somehow predicts that contour tones cannot occur on short vowels (assuming that sequences of features within one segment is barred).

Within the autosegmental theory, contour tones could depending on the language be treated as unitary or composite. Similarly, the occurrence of contour tones on long or short vowels is language specific. While the realisation of composite contour on long vowels is less problematic, that of short vowels involves a collapse of two tones on one segment. Anderson (1978) observes that in this context, composite contour tones are not associated in a one to one fashion with the tone bearing element but rather, more than one element may in some languages be assigned to the same short vowel. This could be schematically represented thus:

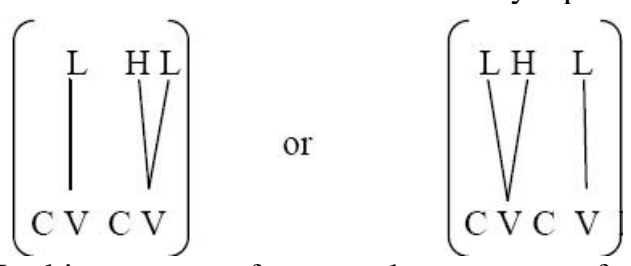

In this paper, we focus on the treatment of contour tones as composite. It is often argued in Igbo as in some other African tone languages that contour tones are mere surface features resulting from different underlying rules which could be language specific. This could equally be deduced from the fact that contour tones result from a situation in which the number of tones is greater than the number of syllables (Vanderhulst, 1988). As postulated by Lojenga (2012), contour tones are a surface phenomenon in African languages which needs intepretation into the underlying tones or tonal melodies. A cross linguistic study of contour tones in African languages shows that they could result from partial spreading, merger of two unlike tones across morpheme boundaries, association of a floating tone to a syllable with an unlike non-floating tone, depressor consonants, historical loss of a syllable e.t.c. Having posited a multi linear approach to the analysis of segmental and non segmental features, the loss or historical loss of a TBU does not necessitate the loss/deletion of the superimposed tone. The following example drawn from Elimelech (1976) as cited in Vanderhulst (1988) buttresses this point. In the Etsako language, the expression 'each $\mathrm{N}^{\prime}$ (noun) involves the reduplication of the relevant $\mathrm{N}$;

10) owa 'house' owowa 'each house'

The underlying form of the above would be rewritten as;

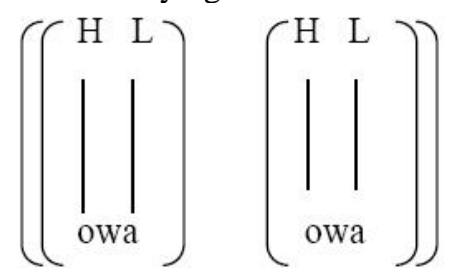

The surface form as seen in example (10) is derived by a deletion rule which deletes the first 'a'. This deletion rule as it seems only affects the segmental tier. Vanderhulst et al (1988) further explains that if Etsako were a language that forbade contour tones on short vowels, the low tone of the deleted 'a' will remain unassociated and therefore receive no phonetic interpretation. However, Etsako allows contour tones on short vowels. This yields a rule that associates the floating tone to the right i.e. to the segment that initiated the deletion of the tone bearing element 'a'. Below is a schematic representation; 


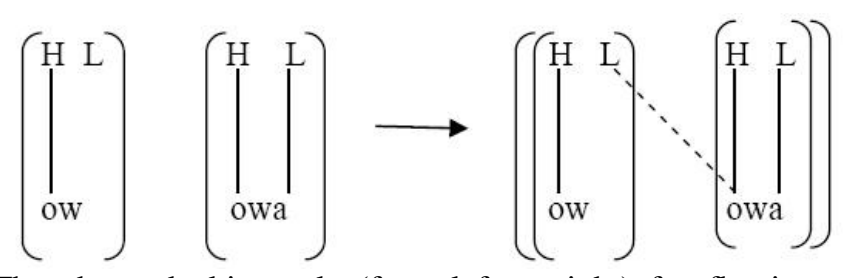

The above docking rule (from left to right)of a floating tone further buttresses the point made earlier, that the loss/deletion of an element of one tier does not necessarily imply the loss of its counterpart. The emergence of a floating tone is described as tonal stability where a vowel or syllable is deleted, but the tone remains behind. As we shall see later, three of the mentioned sources of contour tones (historical loss of segment, association of a floating tone, and merger of two unlike tones across morpheme boundaries) play a vital role in the phonological account of contour tones in Igbo.

\section{Phonological Account of Contour Tones in IgBo}

As noted earlier, Ugorji (2008) proposes an alternative approach to the investigation of contour tones which is at par with the syntactic conditions for the occurrence of a contour tone proposed by Nwachukwu (1995), Emenanjo (1978). Ugorji's analysis follows the autosegmental approach. In this section a review of this alternative proposal is briefly reviewed, bringing to light its strength and weakness. Just as in other existing literature on Igbo contours, Ugorji maintains that there are two contour tones in Igbo (the rising and the falling). He however demonstrates that these contour tones are the outcome of asynchrony between two level tones at the opposite sides of word boundary where the second word begins with a consonant. This is schematized below:

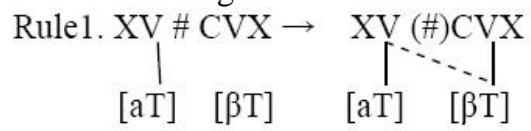

( $\mathrm{T}=$ tone, $\mathrm{a} \& \beta=$ contrasting tone values, $\#=$ word boundary)

From the above representation, it could be deduced that for the occurrence of a contour, there should be "a word boundary involving a final vowel to the left; and to its right another vowel preceded by a consonant". Secondly, the tones on the relevant vowels must contrast. Note that by this assertion, Ugorji (2008) overrules the possibility of contour tones in a strict $\mathrm{V \# V}$ boundary conditions. We shall return to this point shortly. From the posited tone contour condition, he derives two subrules for the falling and the rising tones. For the falling tone, the rule predicts that if a high tone is followed across word boundary by a low tone, a falling tone is realised, if the second word begins with a consonant.

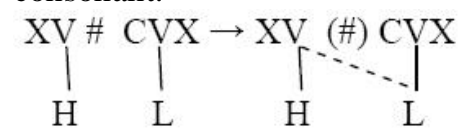

The rule is validated with the following examples:

11.) Chukwu \# di $\rightarrow$ Chukwudi 'personal name'

12.)

He further posits that when the initial consonant on the right side of the word boundary is substituted with a vowel, the tone condition rule is violated and it therefore cannot yield a contour tone even though other requirements are met. Consider the following example:<smiles>[Y][Y10]([H])([H])[Y10]([H])=O</smiles>

For the rising tone, Ugorji postulates that when a low tone is followed across word boundary by a high tone, a rising tone is formed if the second word begins with a consonant. The rule is formalized thus:

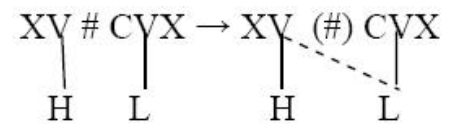

Concrete example: 


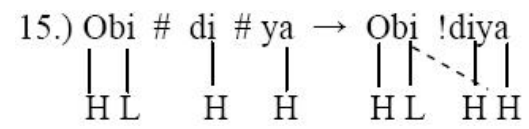

The violation accorded to the contour tone condition in rule 2 is equally applicable here. With this overall analysis, he proves to an extent that contour tones in Igbo are definable in certain phonological contexts. He succeeds in pointing out one of the sources of contour tones in Igbo that, in a way, is one of the different sides of a coin. His contour tone conditions are anchored on the rule of merging two unlike tones across word boundaries (cf Lojenga 2010). The proposed contour tone condition falls short when extended to a larger array of data; especially of the lexicon as we shall see in the subsequent section. Such lexical items as we shall see, seem to persistently violate the proposed tone contour condition. This informs our present research which focuses on giving an appropriate phonological account of these deviating lexical items. While not jettisoning Ugorji's rules, it is clear that his tone condition does not take into account these new set of data. We therefore add to the already proposed rules as espoused in the subsequent section.

\section{Data Presentation And Analysis}

The bulk of the data used is drawn proper names (town names) which are often realised as associative constructions. Also analyzed are lexical words that are derived by compounding and reduplication. Note that the tone of words in isolation (inherent tone of lexical items) might differ when they enter into associative or derivative constructions. Our emphasis is however not on the inherent tones so less attention would be paid to that. The focus point is what happens to their tones in their present status as derived words.

We propose that the realisation of contour tones on the specified lexical items derive from two rules (deletion and docking rules) at the underlying and surface levels. The deletion rule is associated with the segmental tier and the docking rule associated with the non segmental tier. Both rules seem to be interdependent. Rule 1 (deletion rule) states that when two like or unlike vowels occur across morpheme/word boundary, the following vowel assimilates the preceding one if dissimilar and consequently deletes it. This necessitates the second rule. Rule 2 (docking rule) states that a tone that becomes stranded as a result of an elided or deleted segment docks to the following TBU which motivated the deletion of its segment. The following conditions are necessary for the application of both rules;

- Similarity of vowels

- Existence of a clear morpheme (word) boundary

- Tone contrastiveness across morpheme boundary

Where there are dissimilar vowels across morpheme boundary, the left side vowel is first assimilated before deletion.

Below is a schematic representation of both rules;

$\mathrm{XCX} \# \mathrm{XCX} \rightarrow \mathrm{XCXCV}$

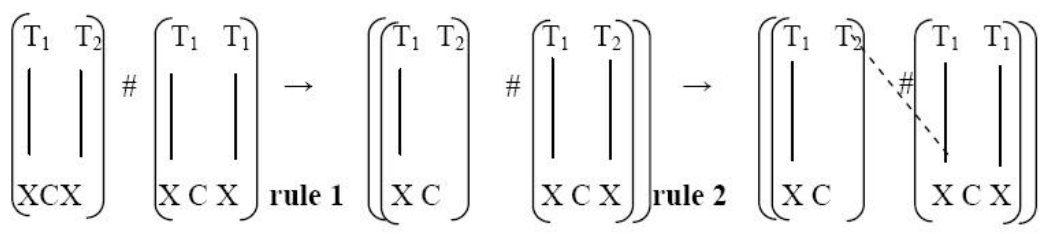

Where $\mathrm{X}=\mathrm{Tbu}(\mathrm{V}), \mathrm{T}_{1} / \mathrm{T}_{2}=$ contrasting tones, \# = morpheme boundary, single bracket = individual word, double bracket $=$ morphologically derived lexical item.

\section{Falling tone}

In the following examples, individual words and their inherent tones are first highlighted. The meaning of some lexical items however seem a little obscure (difficult to recover). Rule 1 and 2 seem to apply predominantly to the falling tone as illustrated below:

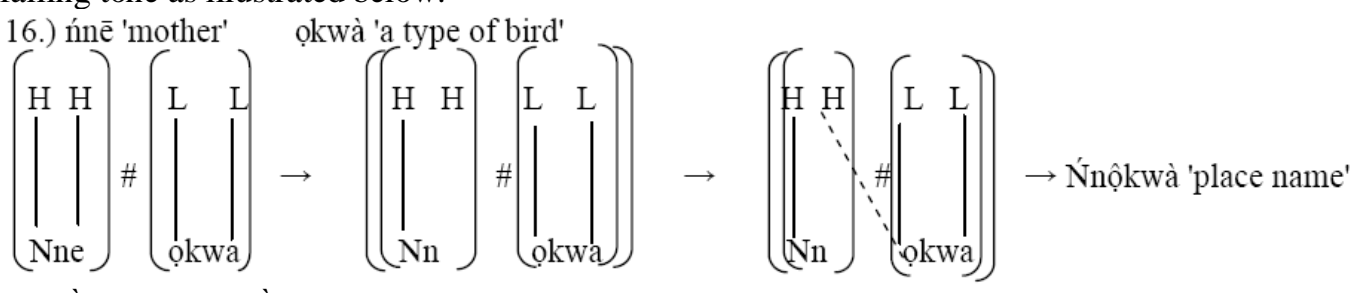

17.) Àgùlù 'name' Èrì 'name'

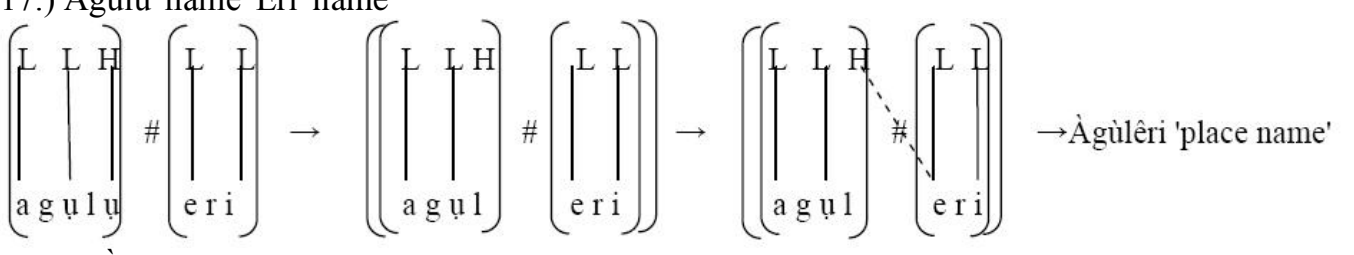

18.) Èkwùlù 'domain/speaking for' óbìà 'visitor, guest' 


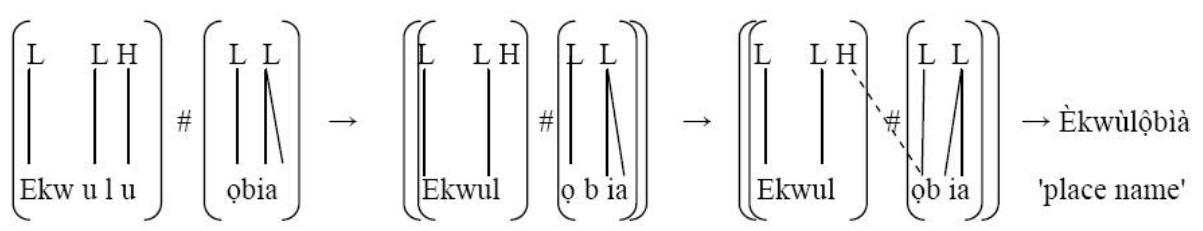

19) òmé(è) 'doer' ka 'surpass' $\rightarrow$ òmèkômè 'notorious person'

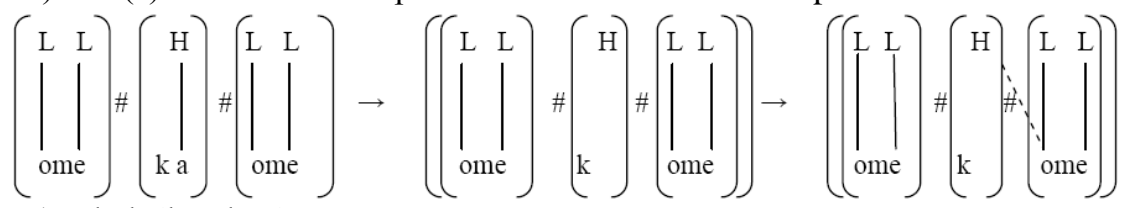

20) àchàlà 'bamboo' ùgò 'eagle'

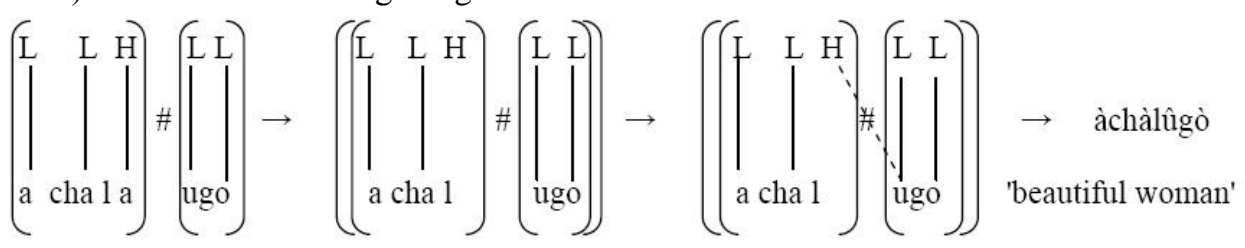

21.) ámā 'open place' àkụ 'wealth'

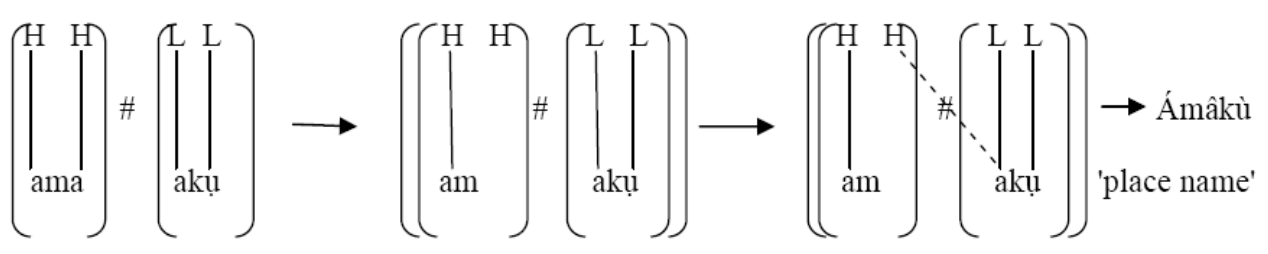

In the examples above, observe that all occurrences of dissimilar vowels across word boundaries motivate the phonological process of assimilation which occurs before the application of rule 1. This is in fulfilment of one of the conditions which is vowel similarity. Some common features of the above examples are the existence of a morpheme boundary, tone contrast across morpheme boundaries which results in an imminent collapse of the relevant tones, and the similarity of vowels which is often induced. At the underlying level as seen in example (16), the high tone is mapped unto the vowel 'e' which becomes assimilated by the vowel 'o' and subsequently deleted by rule 1, leaving its high tone stranded. This instigates the application of rule 2 which docks the high tone (now floating) to the following vowel for the assigning of tone. As is obtained in non linear phonology, no tone is left unassigned, explaining the application of rule 2. The interpretation of these rules at the surface level results in a falling contour tone as in example (16, 17 and 18). Thus the word Nneokwa is realised as Nnokwa, Agulueri as Aguleri, and Ekwuluobia as Ekwulobia. An alternative analysis would be to posit a long vowel to bear the tones, unfortunately, Igbo does not allow long vowels. In examples (19) and (20), we the have general nouns 'omekome and achalugo'. Three morpheme boundaries are recorded in example (19) and two in example (20). In the three boundary word, rule 1 applies to the middle morpheme deleting the vowel 'a' leaving its tone floating. Rule 2 then applies assigning the floating tone to the following vowel 'o'. Same applies to the vowel of the first morpheme 'achala' at the morpheme boundary in example (20). For examples (21), the vowels involved are purely similar vowels whose similarity is not phonologically induced. With the deletion of the last Tbu 'a' of the first morpheme, rule 2 again permits the stranded tones to dock to the following realising in the surface level a falling contour tone (which glides from high to low). From the above data, it is clear that there is no violation of rules that would impede the realisation of a contour tone at the morpheme boundary of two adjacent vowels, other factors being constant. Tone stability is observed in all examples used, supporting the general idea that the two tiers should be kept separate since the loss of a component of one does not imply the loss of another. We come to the conclusion that contour tones are realised at the surface level after the application of several rules which bothers on the loss of a segment or segments (hence the deletion rule) and the association of a floating tone (docking rule).

The rising tone

Next, we turn to the rising tone which as exemplified below is derived from the underlying level following the deletion and docking rules. The following examples are illustrative;

22.) ime\#oka 'place name'

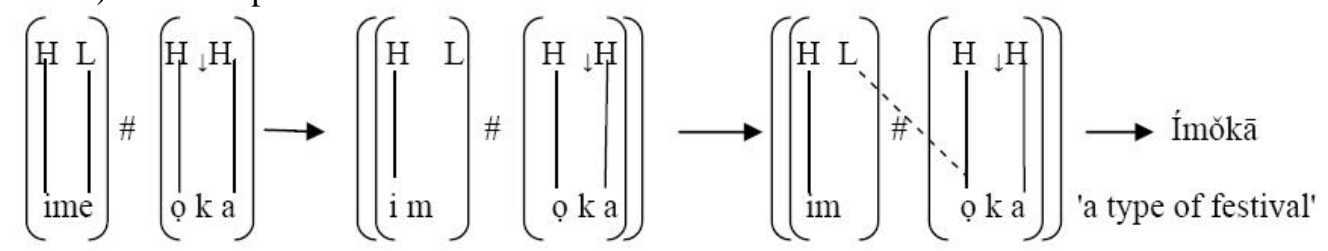

23.) ụ́kà 'conversation' átụ́ 'a type of animal' 


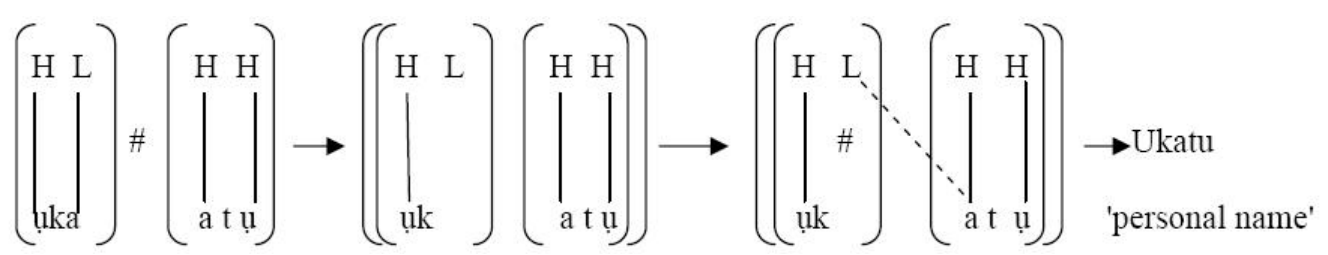

In example (22), two contrastive tones and vowels occur at the morpheme boundary motivating the realisation of rule 1 and 2. The floating low tone as an aftermath of the deletion rule docks to the right, collapsing with a high tone which results as a rising contour tone. This same process is replicated in example (23) except that this time, the vowels occurring at the morpheme boundary are same and not induced. Observe that the three postulated conditions are fully met, aiding the application of rule 1 and 2.

In passing, it is observed that the falling tone seems to be more predominant in the sample used and even Igbo in general. The down pointing arrow in examples (22 and 23)marks a reduced high. Note also that when two similar or non contrasting tones are superimposed on vowels at the morpheme boundary, rule 1 and 2 do not apply even if other conditions are met.

Consider the following example:

[ḿ́bà] \#[ ìsè $\rightarrow$ [ḿbà\#ìsè] 'place name'

From the foregoing, we posit that the motivation of contour tones at the surface level of Igbo lexical words necessarily requires morpheme boundary condition but goes beyond it. The surface realisation of contour tones in independent lexical words could also be traced to the historical loss of a segment (deletion) and the association of floating tones as shown with the numerous examples.

\section{CONCLUSION}

We have attempted to proffer some explanation or derive rules to account for the motivation of contour tones in some morphologically derived lexical words. The deletion and docking rules are used to explain the derivation of gliding tones from the underlying level to the surface level. Thus, the realisation of a contour tone in the data analyzed is an aftermath of an elided segment and the association of its stranded tone to the following tone bearing unit which probably motivated the deletion. These rules draw largely from the autosegmental model of tone analysis. We note that these rules do not necessarily contradict the rules postulated by previous phonological analysis of contour tones but rather complements it by accounting for a set of data that defies the already stipulated conditions. It is equally observed that the merging of tones across morpheme boundaries is restricted to free morphemes (excluding bound morphemes). On a broader perspective, three major sources are posited on a phonological scale to account for contour tones in Igbo; hence, revealing them for what they are, mere surface features to be interpreted as composite rather than unitary.

\section{REFERENCES}

[1] C.U.C Ugorji. (2008). Contour tones in Igbo. Language in India. Vol:8. Issue 2

[2] Constance, K. Lojenga. (2012). Sources of contour tones in African languages. University of Leiden, Amsterdam (hand out).

[3] David Odden. (1992). Tone: African languages. In John Goldsmith (ed.), The handbook of phonological theory. John Oxford: Blackwell Publishers

[4] Emenanjo, E.N. (1978). Elements of modern Igbo grammar. Ibadan: Oxford University Press.

[5] Green, M.M., and G.E. Igwe. (1963). A descriptive grammar of Igbo. Berlin: Akademie Verlag.

[6] Harry Van der Hulst and Norval Smith. (1988). An overview of autosegmental and metrical phonology. In Harry Van der Hulst and Norval Smith (eds.), The Structure of Phonological Rrepresentations I. Dordrecht:Foris.

[7] Joshua Project. (2009). A ministry of the US centre for world mission. U.S.A: Colorado Spri.

[8] Mike Cahill. (1994). A short introduction to autosegmental theory. SIL International.

[9] Nwachukwu, P. A. (1995). Tone in Igbo syntax. Studies in Igbo linguistics 2, Nsukka.

[10] Paul Newman. (1992). Hausa tonology: Complexities in an 'easy' tone language. A Paper Presented at the 23rd Annual Conference on African Linguistics.

[11] Pike, K. (1948). Tone languages. Ann Arbor: The University of Michigan Press.

[12] Stephen, R. Anderson. (1978). Tone features. In V. Fromkin (ed.), Tone: a linguistic survey. New York: Academic Press Limited

[13] Williamson, K. (1972). The Igbo associative and specific constructions. In K. Bogers, H, Vander Hulst and M, Maar ten, The phonological representation of suprasegmentals. Dordretch, USA: Forris Publications. 195-208.

[14] Williamson,K. and Blench,R. (2009). "Niger Congo". In Heine,B. and Nurse,D.(eds.), African languages: An introduction. Eds.. Cambridge: Cambridge University Press.

[15] Yip,M.( 2002). Tone. Cambridge: Cambridge University Press.

Chikelu Ihunanya Ezenwafor is currently a PhD researcher in Linguistics at Scuola Normale di Superiore, Pisa, Italy. 